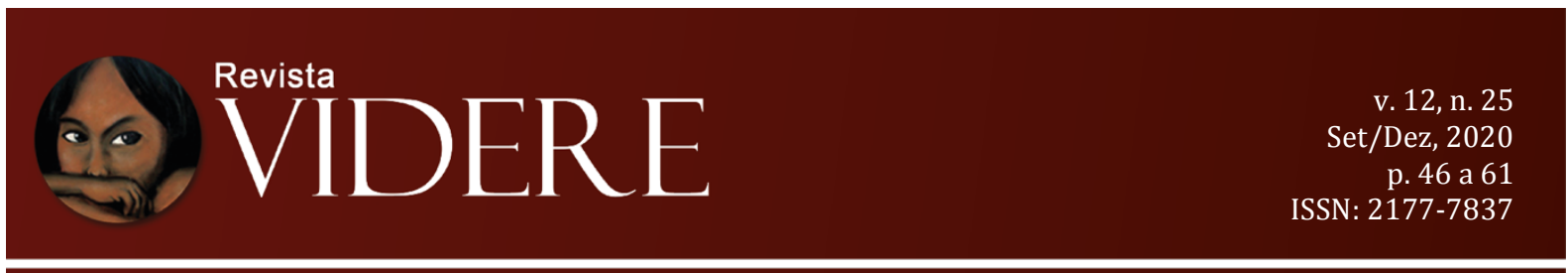

\title{
A EXPANSÃO PRIVADA DO ENSINO SUPERIOR E A AUTONOMIA UNIVERSITÁRIA: relações entre os campos científico e econômico
}

\author{
LA EXPANSIÓN PRIVADA DE LA EDUCACIÓN SUPERIOR Y LA AUTONOMÍA \\ UNIVERSITARIA: relaciones entre los campos científico y econômico
}

\author{
THE PRIVATE EXPANSION OF HIGHER EDUCATION AND UNIVERSITY \\ AUTONOMY: the relations between the scientific and economic fields
}

\begin{abstract}
Felipe Montiel da Silva
Mestrado em Direito a partir do Programa de Pós-Graduação da Universidade La Salle, Canoas/RS Graduado em Direito pela Faculdade de Desenvolvimento do Rio Grande do Sul montielfs@gmail.com Orcid: http://orcid.org/0000-0003-1061-691X
\end{abstract}

Leonel Pires Ohlweiler Pós-Doutor pela Universidade Federal de Santa Catarina. Doutor em Direito pela Universidade do Vale do Rio dos Sinos. Mestre em Direito leonelpires@terra.com.br Orcid: http://orcid.org/0000-0002-2296-675X

\begin{abstract}
Júlia Dutra de Carvalho
Mestra e Doutora em Psicologia Social e Institucional - UFRGS Bacharela em Ciências Jurídicas e Sociais pela Pontifícia Universidade Católica do Rio Grande do Sul (PUCRS) e Graduada em Psicologia pela Universidade Federal do Rio

Grande do Sul (UFRGS). juliadcarvalho@gmail.com

Orcid: http://orcid.org/0000-0002-2113-8039
\end{abstract}

\begin{abstract}
Resumo: através de análise interdisciplinar conjugada a dados bibliográficos e fontes secundárias o estudo pretende averiguar se a expansão privada do ensino superior é capaz de fortalecer a autonomia universitária e contribuir com a diminuição da desigualdade social. A pesquisa foi dividida em três seções. A primeira resgata as teorias do capital humano e do capital intelectual, apresentando os impactos que os modelos de acumulação fordista e flexível provocam na expropriação simbólica do trabalhador. A partir do conceito de campo desenvolvido por Bourdieu no texto "os usos sociais da ciência (2005)" o segundo trecho enfrenta as relações entre ensino e mercado, observando as tendências que formam a autonomia educacional. A última seção mostra os efeitos concretos da expansão privada do ensino superior, referindo, de maneira pontual, como a dominação racial e a desigual divisão social dos bens simbólico-materiais aparecem na prática. $\mathrm{O}$ estudo concluiu que a expansão privada da educação superior contribui com a dessegregação da referida etapa educacional, relegando, ao mesmo tempo, discentes e egressos desprovidos de acúmulo econômico-simbólico às piores posições acadêmico-profissionais.
\end{abstract}


Palavras-chave: Educação. Capital. Desigualdade Social.

Resumen: A través del análisis interdisciplinario combinado con datos bibliográficos y fuentes secundarias, el estudio tiene como objetivo investigar si la expansión privada de la educación superior es capaz de fortalecer la autonomía universitaria y contribuir a la reducción de la desigualdad social. La investigación se dividió en tres secciones. El primero rescata las teorías del capital humano y el capital intelectual, presentando los impactos que los modelos fordista y de acumulación flexible tienen en la expropiación simbólica de los trabajadores. Basado en el concepto de campo desarrollado por Bourdieu en el texto "los usos sociales de la ciencia (2005)" la segunda sección aborda la relación entre la enseñanza y el mercado, observando las tendencias que forman la autonomía educativa. La última sección muestra los efectos concretos de la expansión privada de la educación superior, que se refiere, de manera puntual, a cómo la dominación racial y la desigual división social de los bienes simbólicos-materiales aparecen en la práctica. El estudio concluyó que la expansión privada de la educación superior contribuye a la desegregación de esa etapa educativa, relegando, al mismo tiempo, estudiantes y graduados sin acumulación económico-simbólica a los peores puestos académicos-profesionales.

Palabras clave: Educación. Capital. Desigualdad Social.

\begin{abstract}
Through interdisciplinary analysis combined with bibliographic data and secondary sources, the study aims to investigate whether the private expansion of higher education is capable of strengthening university autonomy and contributing to the reduction of social inequality. The research was divided into three sections. The first rescues the theories of human capital and intellectual capital, presenting the impacts that the Fordist and flexible accumulation models have on the symbolic expropriation of workers. Based on the field concept developed by Bourdieu in the text "the social uses of science (2005)", the second part deals with the relationship between teaching and the market, observing the trends forming the educational autonomy. The last section shows the concrete effects of the private expansion of higher education, referring, in a punctual way, how racial domination and the unequal social division of symbolic-material goods appear in practice. The study concluded that the private expansion of higher education contributes to the desegregation of that educational stage, relegating, at the same time, students and graduates without economic-symbolic accumulation to the worst academic-professional positions.
\end{abstract}

Keywords: Education. Capital. Social inequality.

\title{
1 Introdução
}

A redemocratização do Brasil permitiu a ampliação de inúmeros sonhos, encontrando-se entre eles a democratização do ensino superior. Se durante a segunda metade do século XX a educação terciária esteve reservada à burguesia e à classe média nacional, a primeira década do século XXI apontou em outra direção. Antes de atribuir a ampliação do acesso ao ensino superior à agenda política do Partido dos Trabalhadores é preciso considerar o contexto histórico que conduziu a criação de políticas de ações afirmativas como, por exemplo, o Programa Universidade para Todos (PROUNI).

Durante as Reformas Estatais conduzidas pelo longo mandato presidencial de Fernando Henrique Cardoso as normatizações educacionais receberam a Lei de Diretrizes e Bases da Educação Nacional, LDB. O referido instrumento normativo criou a categoria jurídica instituição particular em sentido estrito (art. 20, inciso I, da LDB), permitindo que instituições de ensino superior confessionais e comunitárias tivessem a chance de adotar a 
forma mercantil, gerando lucros ou dividendos para os quadros sócio-comerciais que passariam a poder mantê-las.

No campo jurídico o momento histórico em questão é simbolizado a partir da descentralização do Estado, entregando à iniciativa privada serviços públicos que por vezes nem sequer eram prestados de maneira universal pela autoridade política nacional. A expansão do ensino superior obedece a referida dinâmica, tornando-se possível afirmar que a dessegregação do ensino superior derivou da conciliação de posições sociais antagônicas trabalhadores, de um lado, e proprietários dos fatores sociais de produção, do outro realizada a partir do Estado. Não é preciso lembrar, contudo, que os pactos locais forjados no interior da luta de classes mundial possuem tempo de duração, apresentando, durante o caminho que os leva à saturação, as contradições que permitem identificar seus beneficiários substanciais.

Com o objetivo de simbolizar a educação e o campo educacional de modo não idealizado, ou seja, esquivando-se das simbolizações que compreendem as atividades do sistema educacional longe das práticas sociais concretas atravessadas pela divisão sócioracial dos bens simbólico-materiais, a pesquisa encara "educação, pobreza e desigualdade social", temas de interesse da Revista Videre, como condições estruturais da expansão universitária havida na primeira década do século XXI. No contexto, a visão axiomática que forja equivalência entre educação e libertação concede espaço para apreensão das contradições estruturais que insculpem as práticas do sistema educacional, apontando que o campo acadêmico-científico articula o acúmulo de capitais que favorece a reprodução ampliada da pobreza e da desigualdade social.

O estudo investigou os efeitos que a expansão privada do ensino superior produz na autonomia universitária e na desigualdade social, analisando, basicamente, as mútuas implicações entre a educação e a economia. A referida indagação permitiu que a pesquisa observasse como o crescimento do controle privado sobre as instituições de ensino repercute na maior ou menor observância às regras impostas pela linguagem científica, verificando, assim, as relações que a privatização do ensino possui com o grau de autonomia das instituições de educação superior.

Os distintos graus de autonomia encontram relação com a emergência de políticas de igualdade social no ensino na medida em que instituições concretamente autônomas possuem maior liberdade para alocar recursos econômicos em ações que não representam o interesse monetário imediato de acionistas, investidores ou das próprias mantenedoras. A autonomia, no contexto, foi utilizada para pensar a capacidade que 
instituições privadas possuem de seguir agendas próprias de ensino, financiamento à pesquisa e assistência estudantil.

É importante referir que a dessegregação do ensino terciário realizada por meio da iniciativa privada aumentou o número dos diplomados, mas manteve, ao mesmo tempo, diferenças substantivas entre diplomas da mesma natureza. $\mathrm{O}$ fenômeno em questão também foi objeto de análise da presente pesquisa, encontrando forte relação com a autonomia que o campo acadêmico-científico possui - ou deixa de possuir - em relação à economia. Não é demais lembrar que a asfixia do poder de refração do campo científico-acadêmico induz os estudantes e diplomados desprovidos de acúmulo simbólico e econômico, ou seja, vinculados à classe trabalhadora, a demandar maior utilização do campo educacional por meio de cursos de especialização, formação continuada, mestrado, doutorado, etc. É curioso, no entanto, que os cursos em questão passaram a ser objeto de intermediação econômica após a Reforma do Estado havida na década de 90 do século XX, mostrando um dos efeitos práticos da privatização do campo acadêmico-científico.

\section{As relações entre economia e educação}

A contradição estabelecida entre o decréscimo dos postos de trabalho e a ampliação da oferta de matrículas no ensino superior ganha dois importantes aliados de compreensão a partir das teorias do capital humano e do capital intelectual, ambas, no entanto, faces da mesma moeda, ou seja, expropriação da vitalidade dos trabalhadores e transposição dos seus saberes para o capital simbólico da produção.

Em meio à década de 60 do século XX Theodore Schultz e Gary Becker, economistas vinculados à Escola de Chicago, observaram que famílias que investiam mais em educação formal extraiam melhores resultados econômicos e melhor colocação dentro dos estratos sociais. Ao termo das análises os pesquisadores encontraram forte vinculação entre os investimentos alocados na educação e o Produto Interno Bruto (PIB), constatando que as cifras ou os recursos econômicos depositados no processo educacional eram equivalentes ou mais importantes que outras formas de investimento direcionado ao crescimento nacional (FRIGOTTO, 2015, p. 216). A teoria do capital humano

propugna que um incremento do investimento nacional em educação fundamentalmente, na formação profissional - acarretará inevitavelmente um incremento da renda nacional, ou seja, causará uma aceleração do crescimento econômico do país. Da mesma forma, um incremento do investimento individual ou familiar em educação causará um incremento da renda individual ou familiar (RODRIGUES, 1997, p. 217). 
Embora as relações tecidas entre a educação e o processo produtivo sejam anteriores às avaliações construídas pelos dois economistas da Escola de Chicago anteriormente mencionados, a teoria do capital humano incorpora a força de trabalho ao capital fixo pertencente à produção. Ou seja: forja equivalência entre a maquinaria e o corpo humano integrado ao processo produtivo.

No plano macroeconômico, a teoria do capital humano considera que o nível de investimento dedicado à escolarização e qualificação da força de trabalho responde pelo maior ou menor índice de produtividade e desempenho da produção, ou seja, o desenvolvimento da atividade industrial e da economia nacional depende da potência com a qual o Estado investe na qualificação laboral dos seus trabalhadores. Dentro da concepção microeconômica, no entanto, o singular índice de investimento que cada família ou indivíduo aloca no percurso educacional representa o indicador de produtividade construído em cada corpo, projetando, a partir do aumento da produtividade através da qualificação, maior ou menor renda e maior ou menor perspectiva de inclusão, exclusão, ascensão, regressão ou manutenção do lugar social (SOUZA, 2006, p. 162-163). A síntese encontra sua melhor expressão em Frigotto:

O suposto básico microeconômico é de que o indivíduo, do ponto de vista da produção, é uma combinação de trabalho físico e educação ou treinamento. Supõese, de outra parte, que o indivíduo é produtor de suas próprias capacidades de produção, chamando-se, então, de investimento humano o fluxo de despesas que ele deve efetuar, ou que o Estado efetua por ele, em educação (treinamento) para aumentar a sua produtividade. A um acréscimo marginal de escolaridade, corresponderia um acréscimo marginal de produtividade. A renda é tida como função da produtividade, donde, a uma dada produtividade marginal, corresponde uma renda marginal. Na base deste raciocínio (silogístico) infere-se literalmente que a educação é um eficiente instrumento de distribuição de renda e equalização social. O cálculo da rentabilidade é efetivado a partir das diferenças entre a renda provável de pessoas que não freqüentaram a escola e outras, semelhantes em tudo o mais (...) e que se educaram. Daí decorrem também as teses relacionadas com a mobilidade social (FRIGOTTO, 1989, p. 44).

A partir do emprego do método dialético conjugado ao olhar material sobre a história Frigotto desafia as construções derivadas da teoria do capital humano, balizando-se, para tanto, nas formas através das quais "os seres humanos produzem socialmente suas condições de existência (FRIGOTTO, 2015, p. 213). Isso significa que as dinâmicas derivadas da produção são replicadas para as instituições e subjetividades, relacionando, no que concerne ao tema ora investigado, o sistema educacional às formas sociais capitalistas.

Por tal razão, mesmo quando a produção industrial rompe com os limites do Estado-nação, fixando bases onde quer que a exploração sobre o trabalho permita custos pouco significativos conjugados a baixos riscos de levantes sociais e generosas isenções 
tributárias (FANON, 1961, p. 99-100), o sul global não deixa de ser compelido por organismos multilaterais a conceder espaços cada vez maiores dentro da organização educacional ao ensino corporativo. Em nenhuma hipótese, entretanto, a educação mercantil abre mão dos recursos públicos transmitidos à base de benefícios fiscais.

Se o capital financeiro se impõe como forma de extração de riqueza ficta ${ }^{1}$ sem necessidade de aquisição de força de trabalho qualificada a partir do capital humano (DOWBOR, 2017, p. 155), o sistema escolar euro-ocidental, por outro lado, permanece como fonte simbólica de nomeação, ocultando as discussões que possam propiciar a tomada de conhecimento sobre as formas através das quais a sociedade materialmente se reproduz.

$\mathrm{Na}$ qualidade de sistema simbólico ${ }^{2}$, o campo científico - produto relativamente autônomo das formas de produção de sentido sobre o real - sofistica a noção de capital humano, engendrando a ideia de capital intelectual. Com a nova roupagem o sistema educacional reformula as pretensões sociais sobre o percurso escolar, forjando, a partir da normalização, novos sentidos ao sistema de ensino.

Se os modelos de controle sobre o trabalho de Frederick Winslow Taylor e Henry Ford estavam alicerçados na concentração do saber produtivo no capital fabril, reduzindo, assim, a capacidade de negociação dos trabalhadores frente aos industriais ao mesmo tempo em que acelerava o ritmo da produção (ANTUNES, 2017, p. 31-47), o avanço do aparato tecnológico aliado ao capital financeiro cria formas mais sofisticadas de favorecimento da produção em detrimento do trabalho assalariado. As novas formas de extração do saber produtivo dos trabalhadores, todavia, não excluem completamente as técnicas utilizadas no mundo industrial.

A ideia de qualificação profissional é adjetivada através da noção de capital intelectual, permitindo que a transferência dos conhecimentos do trabalhador para o capital simbólico da produção deixe de estar vinculada apenas à fragmentação e à especialização das rotinas laborais. O novo método de expropriação do trabalho ataca o conhecimento tácito do sujeito laboral.

\footnotetext{
${ }^{1}$ Segundo Ladislau Dowbor a intermediação financeira deveria financiar a atividade produtiva, no entanto, em verdadeira contradição, a atividade financeira tem se caracterizado pela produção de capital improdutivo, ou seja: "não há como escapar de uma realidade simples: abrir uma empresa, contratar trabalhadores, produzir e pagar impostos é muito mais trabalhoso que aplicar em papéis da dívida pública, mas é o que estimula a economia. Quando você compra papéis eles podem render, mas você não produziu nada, apenas gerou rendimentos sem contrapartida e, a partir de certo nível, isto se torna um peso morto sobre as atividades econômicas em geral (DOWBOR, 2017, p. 155).

${ }^{2}$ Forma de produção de sentido sobre a realidade que parte de premissa estruturada e encontra reestruturação no interior das práticas sociais (BOURDIEU, 1989, p. 9). 
O conceito de conhecimento tácito se distingue dentro das capacidades técnicas e cognitivas, conectando-se, as primeiras, à intuição ligada ao ramo ocupacional de atuação do trabalhador, isto é, às competências técnicas e as variações técnico-conceituais que cada trabalhador realiza em decorrência das disposições que construiu ao longo da própria história. A face cognitiva do conhecimento tácito, por sua vez, remete a captura ou à reconstrução do sistema de percepção/ação do trabalhador, talhando-o à forma e à visão do adquirente do trabalho, ou seja, dos proprietários da produção.

O capital intelectual - também chamado de competência - é medido por meio dos eventos mais ou menos imprevistos que acompanham as rotinas da produção. A capacidade intelectual ou tácita, assim, é quantificada de acordo com a espontaneidade com a qual o trabalhador repara e corrige tais fortuitos internos, isto é, eventos. A chave de compreensão reside na imprevisibilidade. Na medida em que a solução dos eventos fortuitos internos do processo produtivo - não está contida nos manuais, a produção passa a reivindicar a inventividade do trabalhador, transmitindo ao capital fabril ou de serviços formas de solução até então desconhecidas que são integradas à rotina da produção (SANTOS, 2004, p. 7).

Os eventos mobilizam o engajamento subjetivo do trabalhador com o capital, transferindo, após o término da inventividade - esgotamento técnico e cognitivo do trabalhador -, maiores somas de informação ao processo produtivo. A plena expropriação do trabalho dispensa qualquer negociação coletiva ou individual com o corpo há pouco expropriado, aumentando, assim, a disparidade entre capital e trabalho. A valorização da capacidade intelectual de cada indivíduo estreita e desfaz a identidade e o sentimento de pertença entre os trabalhadores (SANTOS, 2004, p. 8), desferindo golpe potente sobre qualquer possibilidade de reivindicação coletiva de caráter reformador - melhores remunerações e circunstâncias de trabalho - ou de aspecto revolucionário - extinção da propriedade privada dos meios de produção.

O enaltecimento do intelecto expressado em torno do conhecimento tácito chega a ofuscar a importância do diploma, evidenciando que a cruzada do capital intelectual não requer apenas o engajamento da intimidade do trabalhador com a produção, mas, por meio da privatização do espaço educacional e do altíssimo índice de saber incorporado à produção a partir das novas tecnologias, impõe ainda maior subalternização ao trabalhador, tornando-o ainda mais descartável. Os ruídos entre a exigência de escolarização e a valoração do trabalho realizada através do capital intelectual merecem ser reproduzidos por meio da escrita de Santos: 
O discurso dominante propaga a exigência de maior escolaridade, mas diz considerar, na avaliação da força de trabalho, as competências, não a qualificação (...) divulga amplamente que o novo trabalhador deverá ser capaz de lidar com os eventos, deflagradores das competências, definidos essencialmente por seu caráter de imprevisão e criatividade no trato, mas investe recursos inestimáveis no controle e padronização das ocorrências do trabalho; afirma formalmente a valorização das competências, que pertencem à esfera privada do indivíduo, mas persegue incansavelmente formas cada vez mais elaboradas de objetivar, expropriar e padronizar o conhecimento tácito, gerando o paradoxo da complexificação do trabalhador coletivo e simplificação e esvaziamento do trabalhador individual, que, ao ser descartado, não deixa marcas pessoais, pois seu valor já foi agregado à mercadoria e ao processo coletivo de trabalho (SANTOS, 2004, p. 9).

A aposta na capacidade intelectual encontra justificativa por intermédio do avanço tecnológico, afirmando que o direito de venda da própria força de trabalho está condicionado ao domínio da tecnologia, à assimilação das novas lógicas sobre o trabalho e à interminável atualização do saber. A contradição, no entanto, é que o próprio avanço tecnológico reestrutura a organização do trabalho, desespecializando os trabalhadores na medida em que transfere os seus saberes mais abstratos para o capital simbólico da produção (RODRIGUES, 1997, p. 220).

Ao mesmo tempo em que a produção exige trabalhadores intelectualmente capazes e, portanto, autônomos, expropria, a partir do avanço tecnológico, as competências técnicas da força de trabalho em velocidade ímpar, abastecendo-se, assim, dos recursos criativos ou das criações derivadas do habitus $^{3}$ de cada trabalhador. Concluída a expropriação das competências técnicas, resta ao trabalhador entregar ou alinhar as suas competências cognitivas às lógicas e aos anseios da produção. A partir do referido momento o desejo da produção passa a ser o desejo do trabalhador, ou seja, o habitus do operário é atualizado aos moldes da produção. Ao fim, as condições do surgimento de levantes, graves e tensões são radicalmente reduzidas na medida em que substituídas pela concorrência do direito de venda do próprio trabalho ou pelo desejo de alcançar posição "dominante" no campo econômico.

Não há ruptura entre o trabalho mecânico e fragmentado da sociedade industrial e o anunciado trabalho intelectivo do sistema de acumulação flexível ${ }^{4}$. Tanto um quanto o

\footnotetext{
${ }^{3}$ A noção de habitus é aqui empregada junto ao conceito de conhecimento tácito, ou seja, técnico e cognitivo do trabalhador. Como o capital intelectual utiliza os "eventos" - fortuitos internos da produção - para capturar o emprego do conhecimento técnico e o engajamento irrestrito do trabalhador em relação à produção, compreende-se, em verdade, que as exigências prescritas pelo capital intelectual atualizam o habitus do trabalhador dentro de uma racionalidade ainda mais econômica ao mesmo tempo em que expropriam as formas particulares de emprego da técnica produtiva de cada trabalhador. Habitus, por sua vez, pode ser compreendido como conjunto durável de disposições que orientam as ações não deliberadas de determinado agente.

${ }^{4}$ O modelo de acumulação flexível encontra conceituação em David Harvey: "a acumulação flexível, como vou chamá-la, é marcado com um confronto direto com a rigidez do fordismo. Ela se apóia na flexibilidade dos processos de trabalho, dos mercados de trabalho, dos produtos e padrões de consumo. Caracteriza-se pelo 
outro, em verdade, engajam a força de trabalho em ações intelectuais, pretendendo, ao fim, transmitir toda capacidade criativa do corpo que opera as máquinas ou aperta as teclas para o conjunto de conhecimentos organizados e titulados pelo proprietário das máquinas e das teclas.

\section{O campo científico e a lógica mercantil}

Adentra-se, aqui, às raias de acirrada discussão: qual o vínculo havido entre as relações de acumulação econômica e o sistema educacional? Há, entre ambos, subordinação plena, autonomia ou liberdade?

Ao refletir sobre os usos sociais da ciência Bourdieu (2004, p. 21) aponta que as expressões culturais são atravessadas por interpretações internas e externas. As abordagens interpretativas internas compreendem dada expressão sócio-cultural como organização de conteúdo e expressão de saber forjado a partir de si. Bom exemplo está contido na ideia que os juristas tendem a fazer sobre a ciência jurídica, compreendendo-a como mecanismo fechado que cria suas regras de organização sem qualquer interferência externa.

Conforme Bourdieu, a

(...) reivindicação da autonomia absoluta do pensamento e da ação jurídicos afirma-se na constituição em teoria de um modo de pensamento específico, totalmente liberto do peso social, e a tentativa de Kelsen para criar uma teoria pura do direito não passa do limite ultra-consequente do esforço de todo o corpo dos juristas para construir um corpo de doutrinas e de regras completamente independentes dos constrangimentos e das pressões sociais, tendo nele mesmo o seu próprio fundamento (BOURDIEU, 1989, p. 209).

A interpretação externa sobre as produções sócio-culturais, por outro lado, compreende que instituições e agentes são formatados e condicionados de maneira objetiva pelas relações econômicas, enxergando, em extensão ao exemplo acima experimentado, a ciência jurídica como aparelho de dominação da burguesia sobre os demais estratos sociais subalternizados (BOURDIEU, 1989, p. 210).

Para Bourdieu, a fuga ou o ponto cego de ambas as interpretação reside no conceito de campo, universo relativamente autônomo habitado por agentes e instituições que reproduzem ou alteram - em maior ou menor escala - as expressões sócio-culturais que conferem sentido à realidade (BOURDIEU, 2004, p. 23). A noção de campo não dispensa a ideia de conflito entre agentes dotados de índice singular de capital simbólico utilizado para

surgimento de setores da produção inteiramente novos, novas maneiras de fornecimento de serviços financeiros, novos mercados e, sobretudo, taxas altamente intensificadas de inovação comercial, tecnológica e organizacional (HARVEY, 1994, p. 146)." 
apropriação dos lugares de imposição do poder de nomeação derivado do capital próprio de cada espaço social, ou seja, agentes dotados de diferentes somas de capital disputam o direito de afirmar o sentido ou a lógica social criada a partir do campo onde estão inseridos.

A partir do conceito de campo, portanto, se torna possível a ruptura com a dicotomia entre as interpretações internas e externas, deslocando a questão para o grau de autonomia titulado por cada campo - espaço - social. De acordo com Carvalho (2017, p. 102) e Cislaghi (2012, p. 271-273) a expansão do ensino superior levada a cabo por programas como o Universidade para Todos, (PROUNI), responde - em certa medida - aos anseios do sistema de acumulação capitalista, demonstrando, portanto, que a economia cria pautas para o sistema educacional. Importante, dentro do referido contexto, é a forma pela qual o sistema de ensino traduz as reivindicações econômicas, escrevendo-as, em menor ou maior medida, a partir das regras de importância construídas dentro do campo escolar.

O tamanho ou a potência do espaço de liberdade relativo titulado por cada campo se conecta ao conceito de refração, ou seja, capacidade que determinado campo possui de traduzir as reivindicações externas com base em suas próprias regras, tornando-as, por muitas vezes, “irreconhecíveis (BOURDIEU, 2004, p. 22).” O aspecto dúbio conferido ao predicado irreconhecível se amolda com perfeição ao sentido do texto.

A capacidade de refração titulada por cada campo pode reescrever as demandas externas em maior ou menor medida, no entanto, dada as relações de interferência constituídas entre os campos, as pressões externas invariavelmente constituirão novas formas de acumulação de capital simbólico dentro de um campo específico, ou seja, a interferência externa baseada na autonomia relativa produz os espaços concorrenciais que constituem o conceito de campo (BOURDIEU, 2004, p. 31). A luta concorrencial se alimenta da possibilidade de tradução das pressões externas a partir das regras estabelecidas em determinado campo, permitindo que os capitalistas de cada campo - agentes que acumulam o capital simbólico próprio do campo onde estão inseridos - se apresentem como vanguardistas dedicados à tradução das reivindicações externas, ação chave para a manutenção do acúmulo de capital simbólico e para manutenção da hierarquia das posições de domínio no campo (BOURDIEU, 2004, p. 27-29).

Embora eventualmente reformule as posições hierárquicas inscritas em determinado campo, a autonomia, medida pelo poder de refração, tende a privilegiar os agentes que titulam maiores somas de capital simbólico, os quais, a partir da intuição derivada do capital que ostentam, se deslocam com interesse "genuíno" para tradução dos temas mais caros às pressões externas, sagrando-se, assim, vencedores na disputa pelas 
novas somas de capital simbólico que dão direito à manutenção das posições mais prestigiosas do campo onde estão inscritos (BOURDIEU, 2004, p. 28).

No texto "Os usos sociais da ciência (2004, p. 26)" Bourdieu traça as linhas que separam o capitalista científico e o capitalista econômico. Segundo Bourdieu, para além de acumularem grandes somas de capitais cientistas e burgueses nada têm em comum, isto é, na medida em que o capital científico estrutura as relações do campo da ciência, o acúmulo de capital econômico não implica, por si só, acúmulo de capital científico. A recíproca trabalha no mesmo sentido. Em outros termos: a acumulação do capital científico não submete de plano as regras do campo econômico. Entretanto, importante destacar o papel da autonomia e da mútua estruturação entre os campos.

A ciência, embora possua regras de reconhecimento e hierarquia próprias, produz resultado dentro do campo econômico, o qual se estrutura, a partir do poder de refração, por meio das suas próprias regras, ou seja, embora a pretensão do cientista seja fazer a melhor ciência e acumular o maior índice de capital científico para aquisição da hierarquia mais alta no campo da ciência, a autonomia do campo econômico aproveita as comunicações científicas a partir das suas próprias categorias, afirmando, assim, o poder de refração e a força do campo econômico.

Ao mesmo tempo, o campo econômico irradia pressões ao campo científico, o qual, a partir do próprio poder de refração, pressuposto da autonomia, traduz os anseios econômicos, dirigindo a produção da ciência - em maior ou menor grau - aos objetos economicamente relevantes. A autonomia, portanto, permite que os agentes alocados em cada campo possam reproduzir a sociedade através das regras a que estão aclimatados ou conformados, ou seja, a partir da disputa pela acumulação do capital simbólico do campo onde estão inseridos (BOURDIEU, 2004, p. 34).

O cientista, a partir da interpretação interna do campo científico, tende a produzir a ciência mais rigorosa, a qual, por meio da interferência e da refração, concentra a imparcialidade dos seus métodos para objetos economicamente valiosos. Trata-se do interesse pelo desinteresse (BOURDIEU, 2004, p. 31). A autonomia, usualmente tomada por liberdade, constrange o cientista à reprodução, integrando-o, por meio da disputa pelo acúmulo do poder simbólico de nomeação e pelo consequente domínio do campo científico, à realidade na qual a ciência não estaria submetida ou constrangida pela economia.

As noções de capital humano e capital intelectual ajudam a compreender as pronúncias e as expectativas econômicas lançadas sobre o sistema de ensino. Urge, portanto, analisar a partir da noção de campo elaborada por Pierre Bourdieu no texto "os usos sociais 
da ciência" a relação estabelecida entre o sistema econômico de acumulação e o sistema escolar, resguardando, entre ambos, relativa autonomia.

\section{A autonomia das instituições de ensino superior em relação à economia}

As teorias do capital humano e do capital intelectual afirmam que enquanto maior for o capital simbólico objetivado na produção, maior será a necessidade de utilização do sistema escolar. A assertiva não carece de lógica, mas, sim, de profundidade.

Ao deixar de considerar a autonomia entre os campos as análises estritamente econômicas sobre o sistema educacional falham ao observá-lo apenas sob a perspectiva de produtor qualificado de trabalhadores. Embora a complexidade dos meios de produção constranja o sistema escolar ao exercício da reprodução técnica, o sistema de ensino, a partir da autonomia e do poder de refração, se organiza a partir de regras próprias, as quais tendem a se conectar com "a reprodução da posição dos agentes e de seu grupo na estrutura social (BOURDIEU; BOLTANSKI, 1975, p. 130).”

A posse das próprias regras e a capacidade de refração se materializa a partir da defasagem que o sistema de ensino apresenta aos anseios da economia, emitindo diplomas - certificados de capacitação - em descompasso com as mudanças tecnológicas que formam a produção (BOURDIEU; BOLTANSKI, 1975, p.131). A partir do capital cultural institucionalizado - diploma (BOURDIEU, 1979, p. 78-79) - a autonomia do campo educacional garante que a produção adquira contingentes de força de trabalho desatualizados, constrangendo, a partir da refração, as imposições da economia. Note-se: a complexidade da maquinaria exige maior uso do sistema escolar, o qual, com base no poder de nomeação derivado da autonomia, reconhecesse e formula, a partir de tempo e parâmetros relativamente próprios, a aptidão dos trabalhadores através do diploma.

A autonomia que o sistema de ensino conserva em relação ao mercado por intermédio do diploma atesta - em caráter irrevogável - a aptidão do diplomado para o exercício de determinada atividade, estabelecendo a expectativa de remuneração média ofertada ao cargo ao mesmo tempo em que defini a nomenclatura e negocia a posição social da ocupação. A irrevogabilidade da competência técnica, contudo, soa como um acinte para os adquirentes de força de trabalho, uma vez que confere aos diplomados certa expectativa ou direito vinculado ao grau obtido. Do ponto de vista dos capitalistas econômicos, o elo entre o diploma e as vantagens laborais redunda no aumento de gastos sobre a produção, merecendo, portanto, belicoso e estratégico combate. 
Para Bourdieu e Boltanski,

Os mestres da economia têm interesse em suprimir o diploma e seu fundamento, ou seja, a autonomia do SE; interessa-lhes a confusão entre o diploma e o cargo. Desejam ter as capacidades técnicas produzidas pelo instrumento de produção de produtores (o SE), sem pagar a contrapartida, ou seja, as garantias que confere a existência de um SE relativamente autônomo. O SE não produz competência (por exemplo, as capacidades do engenheiro) sem produzir o efeito de garantia universalizante-eternizante da competência (o diploma de engenheiro) (BOURDIEU; BOLTANSKI, 1975, p. 136).

Embora o diploma pareça conferir desvantagens àqueles que compram trabalho, algumas considerações importantes devêm ser feitas. A transformação da herança familiar em capital cultural institucionalizado - operação realizada por meio do sistema escolar oculta as formas de transmissão patrimonial que favorecem as classes médias e a burguesa, legitimando, ao fim, a reprodução das desigualdades sociais. Daí porque o encargo gerado pelo diploma não pode ser questionado sem que a função de reprodução social - manutenção da hierarquia simbólica entre as classes - seja colocada em disputa, evidenciando o caráter conservador e antidemocrático do sistema educacional.

De tal sorte,

Os membros das frações dirigentes da classe dominante que, sobretudo por intermédio das grandes écoles, utilizam a titulação em suas próprias estratégias de reprodução, não podem contestar abertamente a legitimidade do certificado escolar e, assim, privar os vendedores de força de trabalho da proteção assegurada pelo diploma sem se privarem de um instrumento muito eficaz de legitimação do acesso às posições dominantes e de dissimulação dos modos diretos de transmissão do patrimônio (BOURDIEU; BOLTANSKI, 1975, p. 139).

A solução, em retorno ao conceito de campo social, reside na supressão da autonomia do sistema educacional público, aumentado a participação da iniciativa privada na oferta educacional. A posse parcial do sistema de emissão de diplomas permite que os donos da produção mantenham os benefícios de camuflagem patrimonial a partir da transformação da herança imaterial em capital cultural institucionalizado, controlando, ao mesmo tempo, o acesso das frações de classe subalternas ao sistema educacional e as prerrogativas derivadas do diploma (BOURDIEU; BOLTANSKI, 1975, p. 139).

\section{Privatização e quebra da autonomia universitária}

Criam-se, assim, fragmentações no sistema de ensino que projetam a classe média e a elite às universidades públicas e às universidades privadas de alto prestígio, limitando, por disposição estrutural, as classes sociais populares ao estudo profissionalizante - tecnólogo - e ao ensino superior vinculado a faculdades e centros universitários. A afirmação encontra amparo nas notas estatísticas do Censo da Educação Superior emitidas 
em 2019 pelo (INEP). No documento, o Instituto Anísio Teixeira atesta que 88,2\% das IES são privadas, dentre as quais $86,2 \%$ estão organizadas academicamente como faculdades (INEP, 2019, p. 8). Entre 2007 e 2017 a rede privada concentrava 75,3\% da totalidade de matrículas ${ }^{5}$ em cursos de graduação, entregando à rede pública $24,7 \%$ das matrículas entre as categorias acadêmicas instituições universitárias e não universitárias (INEP, 2017, p. 14; MONDINI ${ }^{6}$; DOMINGUES, 2005, p. 7).

Mesmo que juntas as universidade públicas e privadas titulem 53,6\% das matrículas (INEP, 2017, p. 4), a conjugação das inscrições concentradas em faculdades e centros universitários - majoritariamente privados - soma 44,2\% (INEP, 2017, p. 5), mostrando, ao fim, que embora 53,6\% dos estudantes frequentem IES que estão organizadas como universidades, ou seja, IES que condensam ensino, pesquisa e extensão, apenas uma fração desconhecida dos $24,7 \%$ das matrículas da rede pública está nas universidades. Ademais, a participação das matrículas públicas em IES de organização acadêmica universitária é inferior ao segmento privado, titular de $28,9 \%$ das inscrições na referida organização acadêmica.

Dentro do referido contexto, merece destaque que as universidades privadas ainda podem aplicar gravíssima sanção aos seus alunos. Exemplo ${ }^{7}$ surge no edital $\mathrm{n}^{\mathrm{o}}$ 013/2019 elaborado pela Universidade La Salle, Canoas/RS. O certame regulou a seleção de acadêmicos bolsistas internos (ABI), de iniciação científica (IC) e de iniciação tecnológica (IT). No item 3, requisitos do bolsista, o edital afirmou junto à alínea "f $\mathrm{f}$ " que o candidato não podia "receber nenhum tipo de benefício ou desconto Institucional, de fomento externo

\footnotetext{
${ }^{5}$ Os dados extraídos das últimas notas estatísticas sobre a educação superior (INEP, 2018, p. 18) indicam que a rede privada concentra $75,4 \%$ das matrículas de graduação. O mesmo documento informa que entre 2008 e 2018 o crescimento das matrículas privadas representou $49,8 \%$ e o crescimento das matrículas públicas $33,8 \%$.

${ }^{6} \mathrm{O}$ Ministério da Educação classifica as instituições de ensino superior em dois grandes grupos de organização acadêmica: a) Instituições Universitárias, que abrigam (i) Universidades; (ii) Universidades Especializadas e (iii) Centros Universitários; e b) Instituições não Universitárias, categoria composta por: (i) Centros Federais de Educação Tecnológica (CEFETs); (ii) Centros de Educação Tecnológica (CETs); (iii) Faculdades Integradas; (iv) Faculdades Isoladas; e (v) Institutos Superior de Educação. No que concerne ao tema, vale destacar que apenas as universidades são obrigadas a conjugar o ensino, a pesquisa e a extensão. Pois bem, a segunda forma organizacional das Instituições de Ensino se conecta à organização administrativa, dividindo-as, conforme os artigos 16 a 20 da Lei de Diretrizes a Bases da Educação Nacional, em: (i) públicas, vinculadas à União, aos Estados e ao Distrito Federal; e (ii) privadas, que fazem parte do sistema de ensino federal, mas podem adotar a forma administrativa (a) privada em sentido estrito (mercantis); (b) comunitárias; (c) confessionais. As duas últimas podem, de acordo com a Lei $\mathrm{n}^{\mathrm{o}}$ 12.101/2009 emitir certificado de entidade beneficente da assistência social, logrando, assim, benefícios fiscais. Verificar mudança derivada da Lei 13.868 de 2019 .

${ }^{7}$ O edital de inscrição ao Programa de Bolsas de Iniciação em Desenvolvimento Tecnológico e Inovação da UNISINOS (UNIBITI 2018-2019) e o edital de inscrição de Bolsas de Iniciação Científica da UNISINOS (UNIBIC 2018-2019) também vedam a concorrência de alunos que recebem bolsa de $100 \%$ do PROUNI no item $\mathrm{n}^{\circ} 10$ de cada certame. Da mesma forma que a Universidade La Salle, a justificativa parece residir na forma de pagamento dispensado a bolsa, ou seja, desconto sobre a mensalidade (UNISINOS, 2018, p. 4; UNISINOSb, 2018, p. 3.)
} 
ou financiamento (FIES, PROUNI, CREDIES, PRAVALER, entre outros) (LA SALLE, 2019, p. 1)".

O motivo do impedimento habita o item 9 do edital, onde a IES informa que o pagamento entregue às bolsas será realizado a partir de desconto de $20 \%$ dos encargos educacionais vinculados ao curso a que o estudante está vinculado. Importante salientar que o manual do bolsista PROUNI é categórico ao afirmar que "não existe impedimento legal para o bolsista do ProUni se candidatar a bolsa de iniciação científica (MEC, 2015, p. 5)", atendendo, assim, à ordem de rechaço à discriminação negativa entre estudantes pagantes e bolsistas ProUni (art. 12, §2º inciso II, Decreto 5.493/2005).

Ademais, indispensável considerar que os bolsistas do PROUNI comprovam fragilidade econômica nos termos dos $\S \S 1^{\circ}$ e $2^{o}$ do artigo $1^{\circ}$ da Lei 11.096/2005, necessitando, para o exercício regular do percurso no ensino superior, de remuneração extraída por meio de estágios ou bolsas de iniciação científica, uma vez que os recursos econômico-familiares são obrigatoriamente baixos.

A balança também ganha peso quando pesa os critérios de concessão da bolsa permanência vinculada ao PROUNI por meio da portaria normativa $\mathrm{n}^{\mathrm{o}} 19$, de 14 de setembro de 2011. Segundo o ato administrativo o valor da bolsa será definido "em edital a ser publicado pela Secretaria de Educação Superior - SESU do Ministério da Educação MEC (BRASIL, 2011, p. 1)”. No entanto, conforme afirma Carvalho (2011, p. 15), "o valor de R \$300,00 foi fixado sem qualquer previsão de atualização monetária, logo para alteração no valor é preciso a edição de nova Portaria Ministerial que venha a substituir a vigente." Alguém ousa imaginar que a bolsa permanência possa ser aumentada via decreto no exercício da agenda política eleita em 2018 ?

Outro dado importante revelado pelas notas estatísticas do Censo da Educação Superior de $2017^{8}$ reside na espécie de contrato de trabalho e na escolarização dos docentes, isto é, no grau de diplomação dos professores. A pesquisa informa que nas instituições públicas de ensino superior os cargos de docência são em geral preenchidos por professores investidos do título de doutor contratados sob regime de trabalho de dedicação exclusiva. Nas IES privadas, no entanto, o grau médio de escolaridade dos professores encontra a titulação de mestre, enquanto os contratos de trabalho são preponderantemente de dedicação parcial (INEP, 2017, p. 6).

\footnotetext{
${ }^{8}$ As notas estatísticas de 2018 lançadas pelo INEP repetem o padrão censitário de 2017 (INEP, 2019, p. 10). 


\section{A EXPANSÃO PRIVADA DO ENSINO SUPERIOR E A AUTONOMIA UNIVERSITÁRIA: RELAÇÕES ENTRE OS CAMPOS CIENTÍFICO E ECONÔMICO}

Mesmo diante das críticas operadas ao padrão euro-ocidental de produção e legitimação do saber é possível identificar por meio dos dados menor concentração de legitimidade e experiência acadêmica nos docentes de IES privadas. A menor concentração de títulos acadêmicos de envergadura, doutoramento, interfere na possibilidade de publicação em periódicos de maior prestígio (BOURDIEU, 2004, p. 36), indicando menor concentração de capital científico ${ }^{9}$ (BOURDIEU, 2004, p. 26-27) em instituições universitárias e não universitárias de organização administrativa privada.

Decorre da legitimidade derivada da concentração de capital científico o agrupamento das classes médias e burguesa brasileira nas universidades públicas. Em última instância, a concentração do capital científico beneficia a concentração de capital social, entregando a agentes e instituições públicas as vantagens da conversão do capital científico em capital econômico ou político (BOURDIEU, 2004, p. 34).

Portanto, seja pelo eventual impedimento de vinculação dos estudantes do PROUNI às bolsas de iniciação científica e tecnológica ou pelo menor grau de escolarização dos professores da rede privada conjugado a bolsas permanência que não recebem atualização frente às altas inflacionárias, o acesso ao ensino superior realizado por meio do Programa Universidade para Todos (PROUNI) cria embaraços a estudantes que habitam corpos racializados e a alunos brancos economicamente frágeis de acordo com a lei, impedindo-os, em diferentes graus e proporções, de acessar a pesquisa e a extensão de maneira remunerada. Tal impedimento, sob o ângulo de estudantes vinculados a famílias de singelo recurso econômico, tende a impor que os alunos provenientes do PROUNI experimentem acesso limitado ao campus universitário, predispondo-os, em regra, ao trabalho técnico-operacional em detrimento do trabalho científico.

\footnotetext{
${ }^{9}$ O capital científico é divido em dois tipos: a) capital científico puro deriva da respeitabilidade que a cientista ou o cientista extrai dos seus pares a partir do exercício dos métodos científicos empregados na produção de artigos, teses e estudos que contribuam com a sofisticação da ciência; e b) capital científico institucionalizado ou burocrático, isto é, capital relacionado à administração dos recursos econômicos e administrativos que criam condições materiais para pesquisa (BOURDIEU, 2004, p. 36). O capital científico institucionalizado está mais próximo à administração do campo científico e menos vinculado à ciência, permitindo que Bourdieu afirmasse que "as relações simbólicas, no interior do campo científico, não têm a clareza penetrante que pode lhe dar uma análise científica destinada a quantificar até mesmo as propriedades mais impalpáveis (...) (BOURDIEU, 2004, p. 39)", indicando, assim, que os ritos burocráticos da ciência não são demasiado científicos, isto é, estão mais dispostos ao exercício da dominação. No que conecta ao tema em discussão, a pesquisa aponta, segundo os dados extraídos do INEP, que os docentes vinculados a IES privadas tendem a concentrar menor índice de capital científico, eis que possuem menor volume de capital cultural institucionalizado (diploma), menor produção em revistas e periódicos de prestígio, extraindo, portanto, menor admiração e reconhecimento dos pares (capital científico puro) e, por fim, menor acesso a cargos elevados que propiciem reconhecimento institucional dos seus capitais científicos. As instituições privadas e os docentes que as habitam tendem a possuir menor capital científico, angariando, assim, menor força na transformação dos capitais que lhes são próprios em capital político ou econômico.
} 
No que refere aos alunos afro-descendentes e a estudantes que descendem dos povos originários brasileiros a privação da experiência de iniciação científica e o correlato óbice à construção paulatina de espaço no campo científico evidencia a dissonância estrutural entre corpos historicamente despidos de capacidade cognoscente (QUIJANO, 1998, p. 229-232; CARNEIRO, 2005, p. 97) e a formação superior, mostrando que por mero acaso ou ação não deliberada dos agentes melhor posicionados no sistema escolar, isto é, por meio do exercício das disposições interiorizadas - habitus - atravessadas pela colonialidade do poder, corpos racializados são institucionalmente convidados a não ocupar em plenitude os espaços tradicionais de construção do conhecimento de matriz euro-ocidental. Obviamente, como aponta Bourdieu, a aquisição das disposições do campo científico durante o percurso universitário já indica a desarmonia entre o habitus do agente e as práticas do campo, mostrando que os alunos vinculados ao PROUNI tendem a ter dificuldades em fazer as escolhas certas, isto é, a incorporar a sutiliza do interesse pelo desinteresse, eis que privados da aquisição congênita - herança e legitimação cultural - dos símbolos necessários ao acúmulo do capital científico (BOURDIEU, 2004, p. 29).

Em retorno à vinculação da classe média e da burguesia brasileira a instituições de ensino superior específicas, frisa-se que a distinção entre os diplomas de ensino superior emitidos por faculdades, centros universitários e universidades não está necessariamente na capacidade técnica dos alunos que os alcançam, uma vez que em decorrência do poder de refração do campo acadêmico-científico todo o diplomado tende a estar desatualizado em relação às exigências da produção (BOURDIEU; BOLTANSKI, 1975, p. 131). A real distinção, portanto, se constrói a partir da valorização outorgada aos diplomas emitidos pelas instituições de ensino que abrigam em seus quadros maiores somas de capital científico, cultural e capital social, ou seja, legitimidade científica adquirida a partir das regras vigentes no campo científico (BOURDIEU, 2004, p. 35-43), domínio dos signos valorizados dentro da cultura ocidental (BOURDIEU, 1979, p. 73) e rede de relacionamento recíproco que determinado agente ou grupo mobiliza a favor de si para conquista de objetivos anteriormente traçados (BOURDIEU, 1980, p. 68).

A diferenciação lega diferentes possibilidades a agentes detentores do mesmo diploma, indicando que a dessegregação do sistema de ensino operada a partir do aumento da escolarização básica, técnica e superior desvaloriza as prerrogativas vinculadas ao capital cultural institucionalizado (diploma) (BOURDIEU, 1978, p. 150), criando tendência prejudicial aos grupos que titulam menores parcelas de bens materiais e imateriais. Em outros termos: a demanda por trabalho qualificado aumentou a oferta educacional a partir do 
ensino privado, inflacionando os diplomas ao mesmo tempo em que reduziu as garantias de certo grupo de diplomados.

A diferenciação criada por meio da "democratização ${ }^{10 "}$ dos diplomas reforça a legitimidade do patrimônio material e imaterial acumulado pela burguesia e pela classe média nacional, uma vez que submete a concentração dos capitais simbólico e econômico ao mérito alcançado a partir do ingresso nas universidades mais valorizadas. Por meio da privatização do sistema de ensino, conforme afirmam Bourdieu e Boltanski (1975, p. 139), os proprietários da maquinaria e os agentes a ela vinculados mantêm a legitimidade dos lugares que ocupam dentro da hierarquia social.

$\mathrm{Na}$ medida em que o acesso à educação superior privada lida com o adimplemento dos custos vinculados à matrícula se verifica que o ensino superior está submetido à concentração de recursos econômicos, ou seja, o acesso à educação passa a ser privilégio daqueles que o podem custear. No que se refere ao ensino superior público a questão não é diferente, uma vez que os vestibulares exigem alto nível de incorporação das disciplinas alocadas junto ao ensino básico, constituindo-se o referido acúmulo como privilégio de raça e classe derivado da transmissão da simbologia eurocentrada (BOURDIEU, 1966, p. 42-46; FREITAS, 2018, p. 320; QUIJANO, 2009, p. 108-114; SOUZA, 2018, p. 28).

Observa-se, dentro do mesmo contexto, que o capital cultural transmitido pela família é indispensável ao sucesso no percurso escolar, demonstrando, assim, que filhos nascidos de famílias menos escolarizadas tendem a apresentar menores índices de êxito na escola (BOURDIEU, 1966, p. 42-46), frustrando as chances de sequer concorrerem aos vestibulares das mais prestigiadas universidades públicas (BOURDIEU, 1966, p. 46-52; FREITAS, 2018, p. 303-317). No referido cenário, os cursos mais tradicionais das Universidades Públicas passam a receber agentes que dividem condições culturais e econômicas desde o berço, as quais costumam ser somadas à frágil e supervalorada descendência européia, ou seja, ausência de semelhança ou pertencimento à população afrodiaspórica ou autóctone-americana (COUTO, 2016, p. 50; SENKEVICS, 2017, p. 23).

A privatização do ensino limita os direitos coletivos derivados do diploma ao aviltar o valor dispensado ao trabalho. Mas os efeitos são ainda maiores. A restrição da autonomia do sistema escolar em relação ao mercado faz com que o sentido atribuído ao

10 A expansão do ensino superior conduzida por organismos estrangeiros (USAID) e por organismos multilaterais (UNESCO, Banco Mundial, OMC) responde à tomada dos serviços públicos do Estado pelo o capital econômico, de forma que a democratização surge, em verdade, como massificação, reduzindo, ainda mais, a autonomia do sistema educacional em relação às demandas do sistema simbólico euro-ocidental. 
percurso educacional esteja simbioticamente vinculado ao sentido da empregabilidade, encontrando nas noções de capital humano e de capital intelectual as conformações que induzem os trabalhadores a crer que a aquisição de títulos os faz mais atraentes aos donos da produção. O título, antes colocado como problema para o capital, passa, a partir da mercantilização do sistema de ensino, à condição de instrumento hábil ao acúmulo econômico no setor de serviços. A defasagem proveniente do poder de refração próprio de um sistema educacional público e autônomo é utilizada como justificativa para qualificação perene, exigindo que os trabalhadores paguem por títulos emitidos pela própria produção.

Assim, o conluio objetivo das estratégias das frações dirigentes da classe dominante com as estratégias dos vendedores de serviços escolares (cujo número tende a aumentar ao mesmo tempo que o volume de detentores de diplomas) contribui para explicar (...) a diversificação do mercado escolar e o desenvolvimento de um aparelho escolar mais diretamente ajustado ao sistema econômico, capaz de fazer concorrência ao monopólio do sistema de ensino do setor público (...) (BOURDIEU; BOLTANSKI, 1975, p. 139).

Enquanto isso, no berço de acumulação dos capitais cultural e social, ou seja, nas universidades públicas e nas universidades privadas de ponta, a burguesia e os estratos médios seguem a transformar as heranças materiais e imateriais recebidas em capital cultural institucionalizado de alto prestígio, assumindo, posteriormente, as posições mais privilegiadas dentro dos campos de formação legitimados pelos diplomas.

\section{Considerações finais}

A expansão do ensino superior brasileiro não pode ser compreendida como dinâmica meramente local, ou seja, derivada das relações sócio-históricas limitadas ao território nacional. $\mathrm{O}$ ensino e o sistema educacional são produtos das formas concretas de produção e reprodução da sociedade, encontrando vínculo com a divisão mundial do trabalho e dos recursos sociais derivados do trabalho. As formas de estruturação dos sistemas de ensino deixam, assim, de corresponder somente às relações de força locais, estabelecendo conexão com as dinâmicas de poder mundiais.

Significa que os maiores investimentos públicos realizados na educação nacional a contar dos anos 30 do século XX encontram relação com a crise econômica que atingiu os países de capitalismo central no mesmo período, permitindo a emergência da política de modernização industrial brasileira. Em determinado período histórico estabelecido no interior de relações políticas e econômicas mundiais surgem e se transformam os projetos e os usos sociais do campo educacional. 
Ao observar a expansão do ensino superior havida a partir da década de 90 do século XX é possível observar o desfazimento da política de industrialização nacional, desarticulando-se a amarra havida entre sofisticação da força de trabalho e aumento da capacidade produtiva nacional. As relações sociais que reduzem o horizonte da indústria nacional não inibem o apetite de crescimento da educação superior, alterando, no entanto, seus usos. Se durante a maior parte do século XX a educação encontra proximidade com o desenvolvimento nacional, no século XXI o crescimento do ensino superior privado não guarda relação com o desenvolvimento das forças produtivas, ensimesmando-se, portanto.

A expansão democrática do ensino superior não possui base em projeto econômico de desenvolvimento interno, entregando valorização simbólica aos estudantes a partir do diploma e generosas subvenções públicas às instituições privadas em geral por meio da concessão de bolsas em programas de ação afirmativa como o ProUni. É inegável que o acesso popular ao ensino superior gera efeitos para além da ideologia, isto é, para muito além da ocultação das formas de reprodução social. O capital simbólico adquirido nas formações terciárias conjugado ao capital político e à educação que estudantes vinculados ao estrato popular - principalmente estudantes negras e negros - proporcionam às instituições de ensino e aos agentes que as habitam reestruturam, em alguns termos, a realidade imediata. É imperioso considerar, portanto, o acesso ao ensino superior como importante conquista estratégica dos movimentos sociais, destacando-se, entre eles, o movimento negro, protagonista na luta pela construção das políticas de cotas (MALOMALO, 2010).

Por outro lado, a dessegregação parcial do ensino superior realizada a partir da educação privada gera efeitos ideológicos deletérios, encontrando-se entre eles a ruptura da expectativa entre aumento da escolarização e melhoria das condições de vida ou ascensão social vertical. A inexistência de política de desenvolvimento industrial retira o Brasil da disputa mundial pela vanguarda científica, diminuindo o emprego ou exploração de mão de obra complexa em proveito da expropriação de trabalhadores vinculados ao setor dos serviços, isto é, campo no qual a maquinaria e o trabalho encontram menor complexidade (BRAVERMAN, 1987, p. 249-302).

Os grandes contingentes de egressos do novo ensino superior privado são conduzidos a navegar numa espécie de mar sem água, encontrando dificuldades ainda maiores em decorrência dos pesos distintos atribuídos aos diplomas de IES universitárias públicas, IES universitárias privadas e IES não universitárias privadas. Com base na teoria dos campos desenvolvida por Pierre Bourdieu o estudo em fase de conclusão admite que tais 
diferenças não derivam, necessariamente, do índice de capital simbólico acumulado por estudantes de cada tipo de IES.

A valorização de cada diploma obedece, em verdade, às contradições que expandem a oferta de educação superior a partir do mercado, conservando os cursos mais concorridos das universidades públicas e privadas mais prestigiadas para estudantes que estabeleceram vínculo com a elite nacional nos períodos colonial, imperial e puerpério da República e para os estudantes vinculados a famílias que forjaram o estrato médio brasileiro entre as décadas de 30 e 70 do século XX. Mesmo diante das políticas de ações afirmativas que integram o ensino superior público, a transmissão de maiores contingentes de estudantes economicamente vulneráveis que habitam corpos racializantes (brancos) e racializados (pretos e pardos) para IES privadas não universitárias conserva a distinção entre diplomas, propiciando que as inserções laborais da elite e da classe média possam ser distinguidas por espécie de ferrete.

O fracasso estruturalmente forjado a partir das formas sociais tende a ser subjetivado pelos egressos das IES privadas mais frágeis, provocando-os à nova e reiterada utilização do sistema educacional privado. Surgem, assim, cursos de extensão, motivação, preparação, mentoria, especialização, mestrado, doutorado e pós-doutorado que alimentam novamente o sistema de ensino privado, ofertando-lhe, assim, uso social intimamente ligado ao mercado e descompassado da concreção das expectativas individuais.

Foi possível identificar, no contexto, que a autonomia universitária sofre constrangimentos severos por meio da expansão privada da educação superior, interferindo nas agendas de ensino, financiamento à pesquisa e assistência estudantil das instituições de ensino terciário. No contexto, concluiu-se que a expansão do acesso privado ao ensino superior encontra contribuição bastante limitada no combate à desigualdade social na medida em que enfraquece a combalida autonomia do ensino em relação ao mercado.

\section{Referências}

ANTUNES, Ricardo. A fábrica da educação: da especialização taylorista à flexibilização fordista. Ricardo Antunes, Geraldo Augusto Pinto. São Paulo: Cortez, 2017.

BOURDIEU, Pierre. A escola conservadora: as desigualdades frente à escola e à cultura, 1966. In: Maria Alice Nogueira; Afrânio Catani (Org.). Escritos de educação. 10. ed. Petrópolis: Vozes, 2008. 
BOURDIEU, Pierre; BOLTANSKI, Luc. O diploma e o cargo: relações entre o sistema de produção e o sistema de reprodução. 1975. In: Maria Alice Nogueira; Afrânio Catani (Org.). Escritos de educação. 10. ed. Petrópolis: Vozes, 2008.

BOURDIEU, Pierre. Classificação, desclassificação, reclassificação. 1978. In: Maria Alice Nogueira; Afrânio Catani (Org.). Escritos de educação. 10. ed. Petrópolis: Vozes, 2008.

BOURDIEU, Pierre. Os três estados do capital cultural. 1979. In: Maria Alice Nogueira; Afrânio Catani (Org.). Escritos de educação. 10. ed. Petrópolis: Vozes, 2008.

BOURDIEU, Pierre. O capital social: notas provisórias, 1980. In: Maria Alice Nogueira; Afrânio Catani (Org.). Escritos de educação. 10. ed. Petrópolis: Vozes, 2008.

BOURDIEU, Pierre. Esboço de uma teoria da prática. In: ORTIZ, Renato. Pierre Bourdieu: sociologia. São Paulo: Ática, 1983.

BOURDIEU, Pierre. O poder simbólico. Rio de Janeiro: Bertrand Brasil, 1989.

BOURDIEU, Pierre. Coisas ditas. São Paulo: Brasiliense, 2004.

BOURDIEU, Pierre. Os usos sociais das ciências: por uma sociologia clínica do campo científico. São Paulo: UNESP, 2004.

BOURDIEU, Pierre. Sobre o Estado. Companhia das Letras. São Paulo, 2012.

BOURDIEU, Pierre. A distinção: crítica social do julgamento. 2. ed. rev. 2. reimpr. Porto Alegre: Zouk. 2015.

BRASIL. Portaria normativa $\mathrm{n}^{\circ} 19$, de 14 de setembro de 2011. Regulamenta o art. 11 da Lei $\mathrm{n}^{\mathrm{o}} 11.180$ de 23 de setembro de 2005, alterada pela Lei $\mathrm{n}^{\mathrm{o}} 12.431$ de 24 de junho de 2011; revoga as Portarias MEC $\mathrm{n}^{\circ} 569$, de 23 de fevereiro de 2006 e $\mathrm{n}^{\circ} 1.151$, de 31 de agosto de 2006. Brasília, DF, 15 set. 2011. Disponível em: http://prouniportal.mec.gov.br/legislacao/legislacao-2011/168-portaria-normativa-mec-n-19de-14-de-setembro-de-2011-texto-compilado/file. Acesso em: 08 mar. 2019.

BRAVERMAN, Harry. Trabalho e capital monopolista: a degradação do trabalho no Século XX. $3^{\text {a }}$ ed. Rio de Janeiro: Editora Guanabara, 1987.

CARVALHO, Cristina Helena Almeida de. Política de ensino superior e renúncia fiscal: da Reforma Universitária de 1968 ao PROUNI. In: 28a. Reunião Anual da Associação Nacional de Pós-Graduação em Educação (ANPED), 2005, Caxambu. 40 anos de PósGraduação em Educação no Brasil: Produção de Conhecimentos, Poderes e Práticas. Rio de Janeiro: Associação Nacional de Pós-Graduação em Educação (ANPED), 2005. Disponível em: http://28reuniao.anped.org.br/gt11.htm. Acesso em 17 jul. 2020.

CARVALHO, Cristina Helena Almeida de. O PROUNI no governo lula e o jogo político em torno do acesso ao ensino superior. Educação \& Sociedade, v. 27, p. 979-1000. 2006. Disponível em: https://www.scielo.br/scielo.php?script=sci abstract\&pid=S010173302006000300016\&lng=en\&nrm=iso\&tlng=pt. Acesso em: 17 jul. 2020. 
CARVALHO, Cristina Helena Almeida de. Uma análise crítica do financiamento do PROUNI: instrumento de estímulo à iniciativa privada e/ou democratização do acesso à educação superior?. In: 34a. Reunião Anual da Associação Nacional de Pós-Graduação e Pesquisa em Educação, 2011, Natal. Educação e Justiça Social. RIO DE JANEIRO: ANPED, 2011. Disponível em: http://flacso.org.br/?publication=uma-analise-critica-dofinanciamento-do-prouni-instrumento-de-estimulo-a-iniciativa-privada-eou-democratizacaodo-acesso-a-educacao-superior. Acesso em: 17 mar. 2020

CARVALHO, Cristina Helena Almeida de. Educação superior privada no Brasil: concentração de mercado e financeirização em simbiose. In: Vera Lúcia Jacob Chaves; Nelson Cardoso Amaral. (Org.). Políticas de financiamento da educação superior num contexto de crise. 1. ed. Campinas: Mercado das Letras, 2017, p. 99-118.

CISLAGHI, Juliana Fiuza. Financiamento do ensino superior no Brasil: novos e antigos mecanismos de privatização do fundo público. In: SALVADOR, Evilásio. et al. (Org.). Financeirização, fundo público e política social. 1ed. São Paulo: Cortez, 2012, v. 1, p. 261284.

COUTO, Márcio Rodrigues. Dificuldades de permanência e diplomação no ensino superior de graduandos negros e graduandas negras na Universidade Federal do Rio Grande do Sul UFRGS. In: Sociologyof Law - Movimentos contra-hegemônicos e direitos humanos em uma sociedade global. 2016, Canoas. ANAIS 2016 - congresso do mestrado em direito e sociedade do UNILASALLE, 2016. p. 23-56. Disponível em: http://repositorio.unilasalle.edu.br/handle/11690/1047. Acesso em: 17 mar. 2020.

DOWBOR, Ladislau. A era do capital improdutivo: por que oito famílias têm mais riqueza do que a metade da população do mundo? São Paulo: Autonomia Literária, 2017.

FANON, Frantz. Os condenados da terra. Lisboa: Editora Ulisseia, 1961.

FREITAS, Lorena Rodrigues Tavares de. A instituição do fracasso: a educação da ralé. In: SOUZA, Jessé; (Org.). A Ralé Brasileira: Quem é e Como Vive. Belo Horizonte: Editora UFMG, 2009, p. 303-328.

FRIGOTTO, Gaudêncio. A produtividade da escola Improdutiva 30 anos depois: Regressão Social e Hegemonia às Avessas. Trabalho Necessário, v. 1, p. 206-233, 2015. Disponível em: https://periodicos.uff.br/trabalhonecessario/article/viewFile/8619/6182. Acesso em: 17 mar. 2020.

INSTITUTO NACIONAL DE ESTUDOS E PESQUISAS EDUCACIONAIS ANÍSIO TEIXEIRA (INEP). Censo da educação superior: notas estatísticas 2017. Brasília, DF: Inep, 2017.

http://download.inep.gov.br/educacao_superior/censo_superior/documentos/2018/censo_da educacao_superior_2017-notas_estatisticas2.pdf. Acesso: 08 mar. 2019.

INSTITUTO NACIONAL DE ESTUDOS E PESQUISAS EDUCACIONAIS ANÍSIO TEIXEIRA (INEP). Censo da educação superior: notas estatísticas 2017. Brasília, DF: Inep, 2018. 
http://download.inep.gov.br/educacao_superior/censo_superior/documentos/2019/censo_da educacao_superior_2018-notas_estatisticas.pdf. Acesso: 29 abril. 2019.

LA SALLE, Universidade. Processo seletivo de acadêmicos bolsistas internos (abi) edital $\mathrm{n}^{\mathrm{o}}$ 013/2019. Canoas, 18 de fevereiro de 2019. Disponível em: https://www.unilasalle.edu.br/uploads/files/0e5224c8e85d5b02cf2f47966a77fd6d.pdf. Acesso em: 17 mar. 2020.

MALOMALO, Bas'Ilele. Repensar o multiculturalismo e o desenvolvimento no Brasil: políticas públicas de ações afirmativas para a população negra (1995-2009). 2010. (482 p.) Tese, Doutorado em Sociologia defendido junto ao Programa de Pós-Graduação em Sociologia da Faculdade de Ciências e Letras da Universidade Estadual Paulista (UNESP), Araraquara, SP, 2010. Orientação: Prof. Dr. Dagoberto José Fonseca. Disponível em: https://repositorio.unesp.br/handle/11449/106247. Acesso em: 17 jul. 2020.

MINISTÉRIO DA EDUCAÇÃO, Secretaria de Educação Superior, Diretoria de Políticas e Programas de Educação Superior, Coordenação Geral de Projetos Especiais para a Graduação. Manual do bolsista PROUNI. Outubro de 2015. Disponível em: http://prouniportal.mec.gov.br/images/pdf/manual_bolsista_prouni.pdf. Acesso em: 08 mar 2019.

QUIJANO, Aníbal. Colonialidad del poder, cultura, y conocimiento en América Latina. In: Anuario Mariateguiano (Lima: Amauta) Vol. IX, $\mathrm{N}^{\mathrm{o}}$ 9. 1998. Disponível em: https://repositorio.flacsoandes.edu.ec/bitstream/10469/6042/1/RFLACSO-ED44-17Quijano.pdf. Acesso em: 17 mar. 2020.

RODRIGUES, José. Da teoria do capital humano à empregabilidade: um ensaio sobre as crises do capital e educação brasileira. In: Trabalho \& Educação - Revista do Núcleo de Trabalho e Educação - ago/dez $\quad-\quad 1997 \quad \mathrm{n}^{\circ} 2 . \quad$ Disponível em: https://periodicos.ufmg.br/index.php/trabedu/article/view/8742. Acesso em: 17 mar. 2020.

SANTOS, Aparecida de Fátima Tiradentes. Teoria do capital intelectual e teoria do capital humano: estado, capital e trabalho na política educacional em dois momentos do processo de acumulação. In: 27a Reunião anual da ANPEd, 2004, Caxambu- MG. anais da 27a Reunião anual da ANPEd, 2004. Disponível em: https://anped.org.br/biblioteca/item/teoria-docapital-intelectual-e-teoria-do-capital-humano-estado-capital-e-trabalho. Acesso em: 17 mar. 2020.

SANTOS, Boaventura de Souza. A gramática do tempo: para uma nova cultura política. $3^{\mathrm{a}}$ ed. São Paulo: Cortez, 2010.

SENKEVICS, Adriano Souza. Cor ou raça nas instituições federais de ensino superior: explorando propostas para o monitoramento da Lei de Cotas / Adriano Souza Senkevics. Brasília: Instituto Nacional de Estudos e Pesquisas Educacionais Anísio Teixeira, 2017. Disponível em: http://portal.inep.gov.br/informacao-da-publicacao//asset publisher/6JYIsGMAMkW1/document/id/689605. Acesso em: 17 mar. 2020.

SOUZA, Jessé. A ralé brasileira: quem é e como vive. São Paulo: Editora Contracorrente, 2018. 
SOUZA, José dos Santos. O recrudescimento da teoria do capital humano (Versão On-line). Cadernos Cemarx, v. 3, p. 159-172, 2006. Disponível em: https://econtents.bc.unicamp.br/inpec/index.php/cemarx/article/view/10875. Acesso em: 17 mar. 2020.

UNIVERSIDADE DO VALE DO RIO DOS SINOS, Unidade acadêmica de pesquisa e pósgraduação. Edital de inscrição ao Programa de Bolsas de Iniciação em Desenvolvimento Tecnológico e Inovação da UNISINOS (UNIBITI 2018-2019). São Leopoldo, 5 de março de 2018. Disponível em: http://www.unisinos.br/images/institucional/iniciacaocientifica/editais-2018-2019/UNIBITI.pdf. Acesso em: 08 mar. 2019.

UNIVERSIDADE DO VALE DO RIO DOS SINOS, Unidade acadêmica de pesquisa e pósgraduação. Edital de inscrição de Bolsas de Iniciação Científica da UNISINOS (UNIBIC 2018-2019). São Leopoldo, 5 de março de 2018. Disponível em: http://www.unisinos.br/images/institucional/iniciacao-cientifica/editais-20182019/UNIBIC.pdf. Acesso em: 08 de mar 2019.

WOLKMER, Antônio Carlos. História do Direito no Brasil. Rio de Janeiro: Forense, 2003.

WOLKMER, Antônio Carlos. Para uma sociologia jurídica no Brasil: desde uma perspectiva crítica e descolonial. REVISTA BRASILEIRA DE SOCIOLOGIA DO DIREITO, v. 4, p. 17-38, 2017. Disponível em: http://revista.abrasd.com.br/index.php/rbsd/article/view/146. Acesso em: 17 mar. 2020.

WOLKMER, Antônio Carlos. Pluralismo Juridico: fundamentos de una nueva cultura del derecho. 2. ed. Madrid: Dykinson, 2018. 324p.

Data de recebimento: 30.04 .2020

Data de aprovação: 19.08 .2020 